\title{
8
}

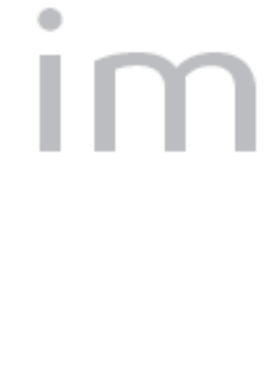

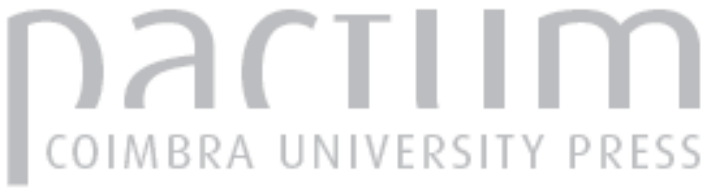

\section{"Che sarà cosa curiosissima e delle più belle": a escultura barroca da Igreja do Loreto}

\author{
Autor(es): $\quad$ Vale, Teresa Leonor M.
}

Publicado por: Imprensa da Universidade de Coimbra

URL persistente:

URI:http://hdl.handle.net/10316.2/45639

DOI:

DOI:https://doi.org/10.14195/0870-8584_13_6

Accessed : $\quad$ 26-Apr-2023 05:09:47

A navegação consulta e descarregamento dos títulos inseridos nas Bibliotecas Digitais UC Digitalis, UC Pombalina e UC Impactum, pressupõem a aceitação plena e sem reservas dos Termos e Condições de Uso destas Bibliotecas Digitais, disponíveis em https://digitalis.uc.pt/pt-pt/termos.

Conforme exposto nos referidos Termos e Condições de Uso, o descarregamento de títulos de acesso restrito requer uma licença válida de autorização devendo o utilizador aceder ao(s) documento(s) a partir de um endereço de IP da instituição detentora da supramencionada licença.

Ao utilizador é apenas permitido o descarregamento para uso pessoal, pelo que o emprego do(s) título(s) descarregado(s) para outro fim, designadamente comercial, carece de autorização do respetivo autor ou editor da obra.

Na medida em que todas as obras da UC Digitalis se encontram protegidas pelo Código do Direito de Autor e Direitos Conexos e demais legislação aplicável, toda a cópia, parcial ou total, deste documento, nos casos em que é legalmente admitida, deverá conter ou fazer-se acompanhar por este aviso.

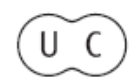




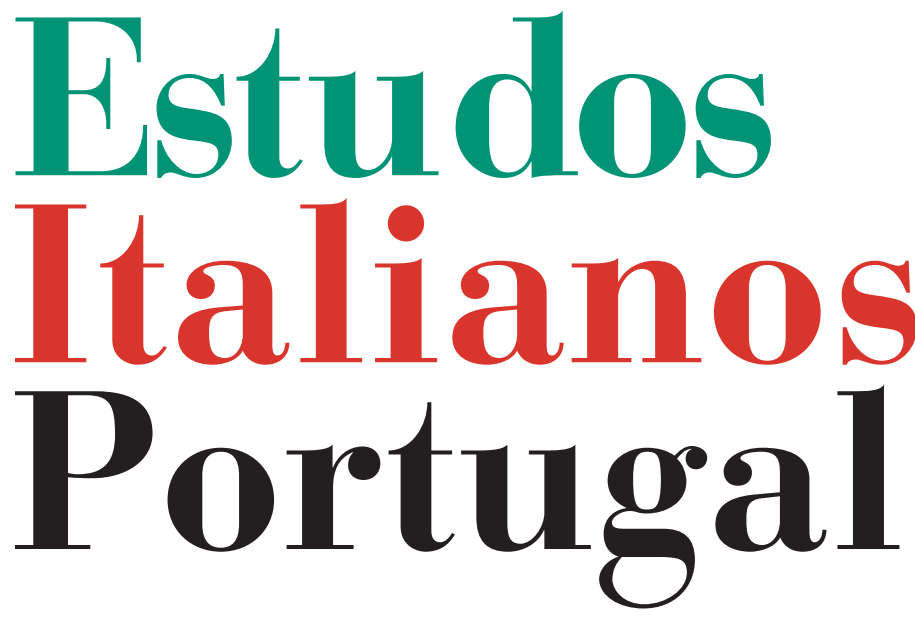

Instituto

Italiano

de Cultura

de Lisboa

Nova Série

$\mathrm{N}^{\mathbf{0}} 13$

2018 


\title{
"CHE SARÀ COSA CURIOSISSIMA \\ E DELLE PIÜ BELLE" \\ A ESCULTURA BARROCA DA IGREJA DO LORETO
}

\author{
Teresa Leonor M. Vale *
}

NOTA PRÉVIA

TENDO JÁ TIDO OpORTUNidAde de tratar da componente escultórica da igreja de Nossa Senhora do Loreto noutras sedes $^{1}$, nomeadamente da sua mais significativa sobrevivência - o busto da Virgem que na sacristia se conserva ${ }^{2}$ - afigurouse-nos pertinente centrarmos desta feita a nossa atenção apenas naquela parte da componente escultórica desaparecida e

* Doutorada em História da Arte, é investigadora do ARTIS-Instituto de História da Arte e docente da Faculdade de Letras da Universidade de Lisboa. O seu domínio de especialização é a arte barroca italiana. É autora de diversos livros e artigos publicados em Portugal, Itália, Reino Unido, França, Espanha e Rússia. teresalmvale@outlook.com

${ }^{1}$ Teresa Leonor M. Vale, Escultura Italiana em Portugal, Lisboa, Caleidoscópio (edição da Dissertação de Doutoramento de 1999), 2004, pp. 138-148; Teresa Leonor M. Vale; Escultura Barroca Italiana em Portugal. Obras dos séculos XVII e XVIII em colecções públicas e particulares, Lisboa, Livros Horizonte, 2005, pp. 11-20; Teresa Leonor M. Vale, Scultura Barocca Italiana in Portogallo. Opere, artisti, committenti, Roma, Gangemi Editore, 2010, pp. 13-21.

${ }^{2}$ Acerca desta obra e para além da bibliografia mencionada na nota anterior, deve ver-se: Antonia Nava Cellini, "Una nuova opera di Francesco Duquesnoy a Lisboa", Estudos Italianos em Portugal, 26, 1966, pp. 3-16 e Fausta Franchini Guelfi, "Sculture genovesi per il Portogallo nel Seicento e Settecento", Teresa Leonor M. Vale, Pedro Flor, (coord.), A Escultura em Portugal. Da Idade Média ao início da Idade Contemporânea: história e património. Actas, Lisboa, Fundação das Casas de Fronteira e Alorna, 2011, pp. 223-238. 
procurar aprofundar a informação já compilada3 . Ocuparnos-emos assim, num verdadeiro exercício de cripto história da arte, tão-só da componente escultórica da retablística da igreja e do famoso apostolado de Filippo Parodi (16301702), que o incêndio subsequente ao terramoto de 1755 impiedosamente consumiu.

\section{INTRODUÇÃO}

A poderosa comunidade italiana residente em Lisboa no século XVII empenhou-se em rechear a sua igreja nacional de Nossa Senhora do Loreto com obras de escultura que, por ser essa comunidade sobretudo oriunda de Génova, eram dominantemente genovesas. Assim, entre 1669 e 1685, podem reconhecer-se duas campanhas de encomendas que se sucedem no tempo:

- uma primeira campanha, que decorre entre 1669 e 1676, e que visa a aquisição de componentes de mármore (colunas, capitéis, anjos) para o retábulo do altar-mor e para os altares laterais da igreja;

- uma segunda campanha de encomendas e aquisições tendo por objectivo a obtenção de catorze estátuas em mármore de Carrara (um inteiro apostolado a que se juntam mais dois evangelistas), destinadas a integrar nichos abertos na nave da igreja, e que se desenvolve entre 1679 e 1685.

\section{A COMPONENTE ESCULTÓRICA DESAPARECIDA: \\ OS RETÁBULOS E O APOSTOLADO}

Acerca da importância das obras de escultura italiana do Seicento existentes na igreja de Nossa Senhora do Loreto, pode

\footnotetext{
3 Tarefa facilitada pela reorganização e catalogação do acervo documental do Arquivo de Nossa Senhora do Loreto, circunstância que determina igualmente a diferente referenciação de alguns dos documentos já por nós referidos, citados e/ou publicados nomeadamente na nossa Dissertação de Doutoramento de 1999. Assim, mencionar-se-ão sempre a cota antiga e a cota actual de todos os documentos em que se registou uma alteração da colocação.
} 
afirmar-se que a do templo nacional dos italianos de Lisboa se constituiu - após a sua reedificação na sequência do incêndio de 1651 - como um paradigma barroco da capital, sobretudo pela quantidade de obras importadas que aí se podia observar ${ }^{4}$. Podemos com efeito, reconhecer um conjunto significativo de obras de arte - no domínio das denominadas artes maiores mas também naquele das artes decorativas que na segunda metade do século XVII recheavam a igreja lisboeta dos italianos.

Quanto às peças de escultura (e também de pedra lavrada), o olisipógrafo Gustavo Matos Sequeira, na sua obra $O$ Carmo e a Trindade, desenvolveu uma primeira abordagem da questão, com base no acervo do arquivo da igreja, identificando a importação das seguintes peças:

- duas estátuas de mármore de Carrara - figurando os apóstolos S. Filipe e Santo André -, uma terceira estátua não identificada por Matos Sequeira, colunas e capitéis para o retábulo do altar-mor, saídos do porto de Génova em 1671;

- colunas e capitéis de mármores vindos de Génova, em 1672 ;

- duas estátuas - figurando S. Pedro e S. Paulo - chegadas a Lisboa no ano de 1681, igualmente oriundas de Génova ${ }^{5}$.

Tendo como ponto de partida este primeiro panorama traçado por Matos Sequeira, demos início à análise do acervo documental do arquivo da igreja do Loreto (Arquivo de Nossa Senhora do Loreto), através da qual pudemos confirmar as afirmações deste olisipógrafo (à excepção do último item

${ }^{4}$ Cf. Carlos Moura, Giacomo Filippo Parodi, José Fernandes Pereira, (dir.), Dicionário de Arte Barroca em Portugal, Lisboa, Editorial Presença, 1990, p. 344.

${ }^{5}$ Cf. Gustavo Matos Sequeira, O Carmo e a Trindade, Vol. II, Lisboa, Câmara Municipal de Lisboa, 1939, p. 241 (referindo-se a documentos da então denominada Caixa C e do Maço $2^{\circ}$ das Contas do Arquivo da Igreja do Loreto, respectivamente). 
acima referido ${ }^{6}$ e ampliar o conhecimento acerca das importaçōes de obras de escultura empreendida pela comunidade italiana de Lisboa na segunda metade do século XVII.

Assim, cremos ter reconhecido as duas campanhas de encomendas a que já fizemos referência:

- uma primeira campanha que decorreu entre 1669 e 1676 e visava a aquisição de componentes de mármore para o retábulo do altar-mor e para aqueles dos altares laterais da igreja;

- uma segunda campanha de encomendas e aquisições, tendo por objectivo a obtenção de catorze estátuas marmóreas (um apostolado e dois evangelistas), destinadas a integrar nichos da nave da igreja, datando as primeiras notícias relativas à mesma de 1679 e as últimas de 1685 .

Quanto à primeira campanha de importações, pode estabelecer-se, com base na investigação realizada no arquivo da igreja do Loreto, a seguinte cronologia:

1669 - Levantamento do espaço destinado a acolher o retábulo do altar-mor e seu provável envio para Génova, uma vez que, através do Livro 15 do Diario da Receita e Despeza da Igreja Italiana do Loreto, nos é dado saber do pagamento (de 18\$300 reis) a Gregório Luís “pella assistência que fes nas medidas e traças do Retabolo da Capella mor (...)"”.

1670 - Realização em madeira de uma coluna e de um capitel a fim de funcionarem como modelo daqueles a realizar em pedra para o retábulo do altar-mor, a que se reporta um pagamento (de $42 \$ 420$ reis) neste ano efectuado a Filipe Ramalho "por huma colona de madera e hum Capitel que

\footnotetext{
${ }^{6}$ Com efeito, foram infrutíferas as nossas buscas no Maço 2. ${ }^{\circ}$ das Contas do Arquivo da Igreja do Loreto no sentido de encontrar o documento a que Matos Sequeira fez referência, o que poderá dever-se a uma deficiente colocação do manuscrito (num outro maço, nos quais os documentos se não encontram numerados nem a sua organização obedece a uma qualquer lógica); tal impossibilidade subsistiu mesmo após a reorganização e catalogação do acervo mais recentemente ocorrida.

${ }^{7}$ Arquivo Nossa Senhora do Loreto (ANSL), Diario da Receita e Despeza da Igreja Italiana de Nossa Senhora do Loreto, 1. a Série, Livro 15, fl. 3.
} 
se lhe mando fazer por molde para os que se hão de mandar fazer a Italia de pedra para o retabolo da Capella mor"s.

1671, 20 Abril - Em Génova, Giovanni Gerolamo Ghersi (certamente parente dos poderosos Ghersi da comunidade de Lisboa) ocupa-se em encontrar um perito em mármores referido como "mestre Orsolino", o qual seria decerto Tommaso Orsolino (1587-1675)9 a fim de poder satisfazer eficazmente a encomenda efectuada desde Lisboa (em carta de 3 de Janeiro, segundo referência do próprio Giovanni Gerolamo Ghersi) pelos provedores da igreja do Loreto, a qual se compunha de "(...) quattro collonne di marmo per fare il retauolo della capella maggiore questo in conformità della Longhessa, è grossessa della misura mandata e solo che le collonne hanno di essere intorte con li suoi quatro base di detto marmo (...)" ${ }^{\prime 10}$. Da leitura deste excerto pode inferir-se que a encomenda, emanada de Lisboa em Janeiro desse ano,

${ }^{8}$ ANSL, Diario da Receita e Despeza da Igreja Italiana de Nossa Senhora do Loreto, 1. a Série, Livro 16, fl. 1; idêntico procedimento já se havia verificado em 1652, então com recurso ao arquitecto Marcos de Magalhães, que desenhou um capitel (depois reproduzido tridimensionalmente em madeira) para os altares das capelas laterais da igreja - cf. ANSL, Diario da Receita e Despeza da Igreja Italiana de Nossa Senhora do Loreto, 1. a Série, Apenso 1. ${ }^{\circ}$ ao Livro 5, p. 13, ref. por Sergio Filippi, La Chiesa degli Italiani, Lisboa, Fábrica da Igreja Italiana de Nossa Senhora do Loreto, 2013, p. 66.

${ }^{9}$ Acerca de Orsolino veja-se sobretudo L. Alfonso, Tommaso Orsolino e altri artisti di "Natione Lombarda" a Genova e in Liguria dal sec. XIV al XIX, Genova, Biblioteca Franzoniana, 1985; V. Belloni, La grande scultura in marmo a Genova (secoli XVII e XVIII), Genova, 1988, pp. 92-108; E. Parma Armani, "Gli Orsolino", La scultura a Genova e in Liguria, (vol. II, Dal Seicento al primo Novecento), Genova, Cassa di Risparmio di Genova e Imperia, 1988, pp. 71-76; Fausta Franchini Guelfi, "Maria Divina Maestra. Un’iconografia mariana per gli scolopi in Liguria”, Arte cristiana, XCI, 2003, pp. 273-278; Fausta Franchini Guelf, "La scultura genovese del Seicento e del Settecento in Corsica. Immagini sacre e arredi marmorei per il territorio del dominio", P. Boccardo, C. Di Fabio, (coord.), Genova e l'Europa mediterranea, Genova, Fondazione Carige, 2005, pp. 259-277.

${ }^{10}$ ANSL, Caixa 1, Maço, 1, doc. 33D, fl. 1 (que corresponde à cota antiga Caixa C, Doc. 19.1), publ. por Teresa Leonor M. Vale, Escultura Italiana em Portugal, cit., Documento 9 . 
se fizera acompanhar senão de um projecto pelo menos de um desenho ou bosquejo (executado por Gregório Luís, atrás referido) com as dimensões do retábulo para orientação de Giovanni Gerolamo Ghersi. Além do mais, uma outra missiva, com data de 13 de Junho de 1671, enviada da capital do reino para Génova e sempre endereçada a Giovanni Gerolamo Ghersi, fornecia outras indicaçôes muito precisas: “(...) quattro colone di pietra ridotta in una sola pietra per ciascheduna, tutte iguali, delle meglio e più belle si possino far fare, com che il colore di esse non sii bianco ne nero, ma bansi di qualche altro colore, di lunghezza e grossura di una colona di legname che li rimettiamo con questa nave Paradisso che suposto dii rotonda, non serve solamente che per la lunghezza e grossura, che per altro ledesideriamo sii ritorta alla forma di quelle della Cappella delli Signori Lomellini (...) pure vi rimetiamo un cappitello di legnamme della grandezza, che hanno di essere li quatro che hanno di andare sopra le dette colone, quali hanno di essere di marmore di Carrara del più bianco si potrà trovare è che siano della migliore fattoria che si potè e potrà inventare" 11 . $\mathrm{O}$ modelo de capitel que então se enviava era decerto aquele pago a Filipe Ramalho no ano anterior.

1673 - Pensamos poder igualmente concluir que estas quatro colunas (com os respectivos capitéis e bases) são as mesmas que no mês de Maio de 1673 foram expedidas para Lisboa desde o porto de Génova. Com efeito, numa carta escrita desde aquela cidade da Ligúria pelo mesmo Giovanni Gerolamo Ghersi, a 13 de Maio de 1673, refere-se o envio de 4 colunas e seus capitéis para o altar-mor da igreja de Nossa Senhora do Loreto ${ }^{12}$.

${ }^{11}$ ANSL, Copiador de Cartas da Junta para diversas Pessoas e Corporaçôes, pp. 16-17, ref. por Sergio Filippi, cit., pp. 65-66.

${ }^{12}$ ANSL, Caixa 1, Maço 1, Doc. 33A (que corresponde à cota antiga Caixa C, Doc. 19.2), publ. por Teresa Leonor M. Vale, Escultura Italiana em Portugal, cit., Documento 10 . 
Se antes tivemos o cuidado de não referenciar tout court um projecto, preferindo a menção a um desenho cotado - as "medidas e traças" referidas em 1669 -, tal fica a dever-se a uma passagem desta missiva de Maio de 1673. Nela, Giovanni Gerolamo Ghersi começa por notar a extrema beleza e perfeição das colunas enviadas, as quais merecem, segundo ele, um enquadramento adequado, pelo que solicita o envio de um desenho com as necessárias dimensóes para que possa mandar proceder à escolha das pedras e à execução de um projecto, para “(...) che l'altare della capella maggiore si facesse di belle varietà di marmi, come qui si fanno che giornalmente non se le pone paramento alcuno, che se mi manderanno la Larghessa che hauerá di esseri si come l'altessa faró fare il dissegno, e lauorare la qualitá delli marmi, che ui hanno da andare che sarà cosa curiosissima e delle piu belle sjano per anche fatte (...)"13.

A 3 de Agosto seguinte o mesmo Giovanni Gerolamo Ghersi volta a escrever aos provedores da igreja do Loreto de Lisboa acerca de quatro colunas (com os respectivos capitéis e bases, tudo de mármore) que cremos serem as mesmas ${ }^{14}$ até porque com a mesma data existe no Arquivo da Igreja do Loreto uma conta relativa aos materiais enviados de Génova para Lisboa. Dessa conta de 3 de Agosto de 1673 constam apenas quatro colunas, quatro capitéis e quatro bases ${ }^{15}$.

1675/76 - Os provedores da igreja dos italianos procedem ao pagamento a Giovanni Gerolamo Ghersi dos “(...) dous Retabolos de Pedreria com dous sacrarios pera os altares colaterais"16.

${ }^{13}$ ANSL, Caixa 1, Maço 1, Doc. 33a , fl. 1-1v. (que corresponde à cota antiga Caixa C, Doc. 19.2,).

${ }^{14}$ ANSL, Caixa 1, Maço 1, Doc. 33B (que corresponde à cota antiga Caixa C, Doc. 19.3), publ. por Teresa Leonor M. Vale, Escultura Italiana em Portugal, cit., Documento 11.

${ }^{15}$ ANSL, Caixa 1, Maço 1, Doc. $33 \mathrm{C}$ (que corresponde à cota antiga Caixa C, Doc. 19.5).

${ }^{16}$ ANSL, Diario da Receita e Despeza da Igreja Italiana de Nossa Senhora do Loreto, 1a Série, Livro 18, fl. 1. 
1676, 28 Janeiro - Já se encontravam em Lisboa dois anjos de mármore (certamente também eles remetidos desde Génova) para o retábulo do altar-mor, pois com esta data é registado no Livro 18 do Diario da Receita e Despeza da Igreja Italiana do Loreto o pagamento de 1.400 reis ao mestre ferreiro Domingos Ferreira pela realização de "duas chauetas de ferro que seruirão pera segurar os dous anjos de marmore do Retauolo da Capella mor" 17 .

1676, 8 Setembro - Continuam a chegar a Lisboa "pedras lavradas”, vindas de Génova na nau Loreto ${ }^{18}$, efectuando-se nesta data um pagamento pelo seu transporte da nau até à praia e daí até à igreja ${ }^{19}$.

1677, 30 Janeiro - No processo de envio de medidas a partir de Lisboa e realização de cantaria lavradas em Génova algo terá corrido menos bem - envio de medidas incorrectas ou deficiente interpretação das mesmas -, pois nesta data encontramos entre as receitas da igreja a quantia de 10.000 reis resultante da venda das pedras lavradas de um dos altares laterais por não servirem ${ }^{20}$.

Neste mesmo ano de 1677 terá vindo de Itália - por acção da comunidade italiana de Lisboa - não apenas obras de arte

${ }^{17}$ ANSL, Diario da Receita e Despeza da Igreja Italiana de Nossa Senhora do Loreto, 1a Série, Livro 18 , fl. 5.

${ }^{18}$ Nos documentos que tivemos oportunidade de consultar no ANSL acerca da importação de escultura e pedraria de Génova frequentemente se referencia o nome da embarcação que efectua a viagem entre Lisboa e aquele porto da Ligúria. Pelo que nos foi dado constatar, um dos navios mais frequentemente envolvidos no transporte destas peças é a nau Nossa Senhora do Loreto, do capitão Giovanni Agostino Germano, precisamente a mesma que (efectuando certamente com regularidade o trajecto Lisboa/Génova) conduz até ao porto de Génova a embaixada enviada pela coroa portuguesa à Santa Sé em 1675 e de que o principal protagonista era o bispo de Lamego (e depois arcebispo de Braga), D. Luís de Sousa - cf. Teresa Leonor M. Vale, Diário de um Embaixador Português em Roma (1676-1678), Lisboa, Livros Horizonte, 2006.

${ }^{19}$ ANSL, Diario da Receita e Despeza da Igreja Italiana de Nossa Senhora do Loreto, 1a Série, Livro 18, fl. 6.

${ }^{20}$ ANSL, Diario da Receita e Despeza da Igreja Italiana de Nossa Senhora do Loreto, 1a Série, Livro 18 , fl. 8. 
mas também um artista. João Baptista Jacovo é o aportuguesamento do nome deste escultor que então se deslocou a Lisboa a fim de lavrar pedras para a igreja do Loreto ${ }^{21}$.

Já em 1672, data de uma listagem dos italianos residentes em Lisboa que no Arquivo da Igreja do Loreto se conserva e que tivemos ocasião de publicar na nossa Dissertação de Doutoramento, um outro artista se contava entre estes. Trata-se de um milanês referido como João Baptista Pintor ${ }^{22}$ e em 1681 estaria igualmente na capital o pintor Giovanni Domenico Ponti (João Domingos Ponte), responsável pela execução dos painéis do tecto da igreja, pois assina um documento como "Gio Dominico Ponte"23.

Quanto à segunda campanha de importações por nós considerada, ela visava essencialmente trazer até Lisboa o apostolado destinado a figurar em nichos abertos na nave da igreja do Loreto.

1679 - A 4 de Agosto regista-se o pagamento de duas estátuas, figurando respectivamente $S$. João e $S$. Tomé, que Francesco Bartolomeo Ghersi enviara de Génova ${ }^{24}$. No mesmo ano verifica-se igualmente a chegada a Lisboa de dois apóstolos, pagando-se no ano seguinte a quantia de $17 \$ 600$ reis "(...) que se gastaram de conduzir os Apostolos de bordo

${ }^{21}$ Cf. Gustavo Matos Sequeira, cit., p. 241; cf. também A. Ayres de Carvalho, D. João Ve a Arte do Seu Tempo, Vol. II, Lisboa, Edição do Autor, 1962, pp. 87-89 22 ANSL, Caixa VII, Doc. 42.1. fl. 2, publ. por Teresa Leonor M. Vale, Escultura Italiana em Portugal, (...), Documento 7.

${ }^{23}$ ANSL, Diario da Receita e Despeza da Igreja Italiana de Nossa Senhora do Loreto,

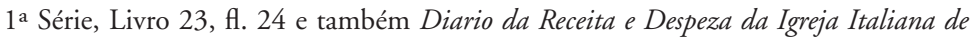
Nossa Senhora do Loreto, $1^{\text {a }}$ Série, Livro 24, fl. 22 e Diario da Receita e Despeza da Igreja Italiana de Nossa Senhora do Loreto, 1a Série, Livro 26, fl. 27; acerca de Giovanni Domenico Ponti ver Vítor Serrão, "A pintura antiga na igreja de Nossa Senhora do Loreto", Nunziatella Alessandrini, Teresa Bartolomei, (coord.), Chiesa di Nostra Signora di Loreto 1518-2018 - Una chiesa italiana in terra portoghese, Lisboa, Fábrica da Igreja Italiana de Nossa Senhora do Loreto, 2018, pp. 147-179 e a bibliografia aí indicada.

${ }^{24}$ ANSL, Diario da Receita e Despeza da Igreja Italiana de Nossa Senhora do Loreto, 1a Série, Livro 21, fl. 17. 
da Nao Sancta Roza, a tè arma-los nos seus nichos" ${ }^{25}$. Estas duas estátuas de apóstolos poderiam ser aquelas supramencionadas ou eventualmente as de S. Filipe e de Santo André, a que alude uma carta remetida de Génova, precisamente por Francesco Bartolomeo, a 22 de Agosto de $1680^{26}$.

1680 - No final deste ano terá ocorrido a chegada de uma outra estátua, não identificada ${ }^{27}$.

1681 - Chegada ao porto de Lisboa de uma estátua figurando S. Tiago, registando-se a 30 de Outubro o pagamento de “(...) Rs sinco mil e sentos e sinquenta que se gastarão a saber 3\$650 que se derão a dezaseis Mariolas que trouxerão o Apostolo Santiago da praya the a Igreja, $1 \$ 200$ e ó Barquo, 400 Rs que se derão a huns marinheiros que ajudarão a por o dito Apostolo no nicho" 28 .

Neste mesmo ano de 1681 terão chegado a Lisboa as estátuas de S. Pedro e S. Paulo que, segundo Gustavo Matos Sequeira, terão custado $121 \$ 695$ reis $^{29}$.

1682 - Chegada a Lisboa dos apóstolos S. Bartolomeu e S. Mateus, pois com a data de 12 de Julho, no Livro 24 do Diario da Receita e Despeza da Igreja Italiana do Loreto, reconhece-se a referência a "(...) noue mil e duzentos Rs que se gastarão com os dous apostolos S. Bartholameo e S. Matheus que vierão de Genova na Nao Sta. Caza do Loreto à saber $1 \$ 200$ rs de dous barcos, $6 \$ 400$ rs de caretto a dezaseis homens, e $1 \$ 600$ rs à gente da Nao que trabalharão dous dias na Igreja com elles"30.

${ }^{25}$ ANSL, Diario da Receita e Despeza da Igreja Italiana de Nossa Senhora do Loreto, 1a Série, Livro 22, fl. 16.

${ }^{26}$ ANSL, Caixa 1, Maço 1, Doc. $33 \mathrm{E}$ (que corresponde à cota antiga Caixa C, Doc. 19.4), publ. por Teresa Leonor M. Vale, Escultura Italiana em Portugal, cit., Documento 12.

${ }^{27}$ ANSL, Copiador de Cartas da Junta para Diversas Pessoas e Corporaçôes, p. 49 ref. por Sergio Filippi, cit., p. 67.

${ }^{28}$ ANSL, Diario da Receita e Despeza da Igreja Italiana de Nossa Senhora do Loreto,

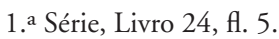

${ }^{29}$ ANSL, Maço 2. ${ }^{\circ}$ das Contas, cit. por Gustavo Matos Sequeira, cit., p. 241.

${ }^{30}$ ANSL, Diario da Receita e Despeza da Igreja Italiana de Nossa Senhora do Loreto, 1. ${ }^{a}$ Série, Livro 24, fl. 19. 
1683 -A 31 de Janeiro de 1683 ainda se paga a Dionisio do Basto 500 reis (mais 200 reis ao moço que o ajudou e outros 100 reis aos mariolas que igualmente o ajudaram) "(...) de dous dias que gastou em aprestar pera por o apostolo S. Matheus no seu nicho"31.

Já no dia 26 de Abril, aportava a Lisboa a estátua do apóstolo S. Simão, com a qual se gastaram 4.800 reis assim registados em Abril no Livro 25 do Diario da Receita e Despeza da Igreja Italiana do Loreto: "(...) a saber 800 rs de hum Barco que desimbarcou o Apostolo S. Simão, e $4 \$ 000$ de todos os mais gastos the se por no seu Nicho"32.

1684 - Neste ano terão chegado a Lisboa as estátuas de dois evangelistas, com os quais se despenderam 8.900 reis - "(...) gastos que se fizerão nos dois Euangelistas que se tirarão de bordo da Nao Loreto a the porem na Igreja nos seus nichos" 33 .

Em síntese, pela análise da bibliografia e sobretudo pela abordagem efectuada do acervo documental do Arquivo da Igreja do Loreto, estabelecemos a importação e chegada a Lisboa das seguintes estátuas de apóstolos: S. Filipe (1680), Santo André (1680), S. Pedro (1681), S. Paulo (1681), S. Tiago Maior ou Menor (1681), S. Bartolomeu (1682), S. Mateus (1682), S. Simão (1683). Quanto aos evangelistas chegados em 1684, eles seriam certamente aqueles dois que não são simultaneamente apóstolos, ou seja, $\mathrm{S}$. Marcos e $\mathrm{S}$. Lucas. Assim, apenas desconhecemos a chegada a Lisboa de quatro estátuas do apostolado: S. Tomé, S. Judas Tadeu, S. Tiago Maior ou Menor e S. João (também evangelista).

${ }^{31}$ ANSL, Diario da Receita e Despeza da Igreja Italiana de Nossa Senhora do Loreto,

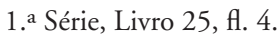

${ }^{32}$ ANSL, Diario da Receita e Despeza da Igreja Italiana de Nossa Senhora do Loreto,

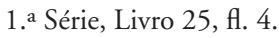

${ }^{33}$ ANSL, Diario da Receita e Despeza da Igreja Italiana de Nossa Senhora do Loreto, 1. a Série, Livro 27, fl. 3. 
Embora nos tenha sido dado encontrar referências documentais acerca da importação de todas as oito estátuas mencionadas (às quais se juntam os dois apóstolos referidos por Gustavo Matos Sequeira), sabemos da existência de um apostolado completo na igreja de Nossa Senhora do Loreto, sobretudo através de descriçóes setecentistas - quando o programa escultórico da igreja se encontrava completo e ainda não havia sido destruído pelo terramoto de 1755 - que nos permitem reconhecer a existência de estátuas de mármore branco figurando os apóstolos e os evangelistas, integradas em nichos abertos coroando a segunda cimalha da nave ${ }^{34}$. Teríamos assim comprovadamente um conjunto de pelo menos catorze estátuas no interior da igreja dos italianos de Lisboa.

Tendo em consideração a origem maioritariamente genovesa da comunidade italiana residente em Lisboa e os seus contactos profissionais mantidos com Génova, afigura-se natural a aceitação do contexto da produção escultórica daquela cidade da Ligúria como aquele em que preferencialmente se efectuavam as encomendas dos provedores da igreja do Loreto. Assim, não se revela surpreendente encontrar o nome do escultor Filippo Parodi associado à autoria de algumas das estátuas do Loreto.

Tanto Júlio de Castilho ${ }^{35}$ como Gustavo Matos Sequeira ${ }^{36}$ haviam já referido tal autoria socorrendo-se da obra de Pietro Guarienti (1753), na qual se mencionava que Parodi "Per la Chiesa poi di Loreto della nazione italiana di Lisbona fece molte statue, che si fano bene distinguere da altre che ivi si trovano" 37 .

${ }^{34}$ Cf. Pe. António Carvalho da Costa, Corografia Portugueza e Descripçam Topografica do Famoso Reyno de Portugal, Vol. III, Lisboa, Officina Real Deslandiana, 1712, p. 478; Gustavo Matos Sequeira, cit., p. 235 e Júlio de Castilho, Lisboa Antiga. Bairro Alto, $3^{\text {a }}$ edição, Vol. II, Lisboa, Câmara Municipal de Lisboa, 1955, pp. 32-33.

${ }^{35}$ Júlio de Castilho, cit., pp. 40-41.

${ }^{36}$ Cf. Gustavo Matos Sequeira, cit., p. 235.

${ }^{37}$ Pietro Guarienti, Abecedario Pittorico del M.R.P. Pellegrino Antonio Orlandi, Veneza, Appresso Giambatista Pasquali, 1753, p. 170. 
Posteriormente foi Carlos Moura quem, recorrendo a bibliografia ainda não abordada por outros autores, nomeadamente a obra de Carlo Giuseppe Ratti, Vite de' Pittori, Scultori et Architetti Genovesi ${ }^{38}$, procurou clarificar a questão, identificando as quatro estátuas dos evangelistas como sendo aquelas realizadas por Parodi, por volta de 1679$1780^{39}$. Contudo, num manuscrito do mesmo autor, datado de 1762 e intitulado Storia de' Pittori, Scultori et Architetti Liguri e de' Forestieri che in Genoa Operarono, que se conserva no Archivio Storico del Comune di Genova ${ }^{40}$, refere-se que as estátuas realizadas por Parodi para a igreja do Loreto de Lisboa foram as de S. Judas Tadeu, S. Matias, S. Filipe e S. Marcos.

Independentemente da questão da precisa identificação das estátuas, no contexto da obra escultórica de Filippo Parodi $^{41}$ as quatro peças esculpidas para o Loreto integram-se num período particularmente fértil - ao qual correspondem diversos pagamentos relativos a obras não apenas pétreas mas também em madeira, detentoras de um carácter mais decorativo, realizadas para famílias da aristocracia genovesa ${ }^{42}$.

Este momento da actividade de Parodi precede imediatamente o início da sua produção dirigida ao Veneto (Veneza e

${ }^{38}$ Carlo Giuseppe Ratti, Vite de’ Pittori, Scultori et Architetti Genovesi, Vol. II, Genova, Stamperia Casamara, 1768.

${ }^{39}$ Cf. Carlos Moura, "Giacomo Filippo Parodi”, José Fernandes Pereira, (dir.), Dicionário de Arte Barroca em Portugal, Lisboa, Editorial Presença, 1990, p. 344.

${ }^{40}$ Com a cota Molfino 44 (108) - cf. Storia de'Pittori, Scultori ed Architetti Liguri e dé Forestieri che in Génova Operarono secondo il Manoscrito del 1762, (edição de M. Migliorini), Genova, Istituto di Storia dell'Arte, 1997.

${ }^{41}$ Acerca de Parodi, cf. por comodidade Mariangela Bruno e Daniele Sanguineti, "Parodi, Filippo", Dizionario Biografico degli Italiani, Vol. 81, 2014 (disponível online), onde se indica exaustivamente toda a bibliografia sobre o artista, das fontes setecentistas, manuscritas e impressas, aos contributos mais recentes.

${ }^{42}$ Cf. E. Gavazza, "Documenti per Filippo Parodi. L'altare del carmine e la specchiera Brignole” Arte Lombarda, 58-59, 1981, pp. 29-37 (p. 34) e Alvar GonzálezPalacios, Il mobile in Liguria, Genova, Sagep, 1996, pp. 77-96 (p. 80). 
Pádua $)^{43}$. Indiscutível é o facto de estas estátuas de Parodi e toda a restante componente escultórica genovesa do templo nacional dos italianos terem tido uma enorme importância para a divulgação e difusão da escultura barroca italiana em Portugal. É aliás a comunidade italiana, que sustenta estas campanhas de importação de escultura para a sua igreja, que propicia também a importação de peças afins para outros espaços da capital portuguesa. Talvez o mais eloquente exemplo do que acabamos de afirmar seja a encomenda de um outro apostolado marmóreo complementado por estátuas de evangelistas, destinado a animar o interior da igreja do colégio de Santo Antão-o-Novo da Companhia de Jesus.

Com efeito, e como já tivemos ocasião de estudar ${ }^{44}$, ainda na década de setenta do século XVII, decidem os padres inacianos proceder à encomenda de um inteiro apostolado, destinado a figurar nos nichos abertos na nave central da igreja. Assim, e sabendo como a Companhia, ciosa de manter o "modo nostro", alimenta estreitos contactos com Roma (onde se encontra a cabeça da ordem) e fideliza os seus artistas, recrutando-os com frequência entre as suas fileiras (ou chamando-os a fazer parte destas), é interessante constatar como um elemento fundamental nesse processo é Giovanni Battista Garvo, mestre pedreiro e escultor já residente em Lisboa em $1672^{45}$.

${ }^{43}$ Carlos Moura aceita que este período surge na sequência de uma segunda estada de Parodi em Roma (entre 1668 e 1674), de acordo com o que propóe Paola Rotondi Briasco (Filippo Parodi, Génova, Università di Genova, 1962, p. 66); todavia, Rudolf Wittkower afasta essa hipótese, considerando mesmo a obra de Rotondi Briasco se apresenta pouco fiável em vários aspectos - cf. Rudolf Wittkower, Art and Architecture in Italy: 1600-1750, $3^{\mathrm{a}}$ edição, Londres, Penguin Books, 1973, p. 297 (1. ${ }^{\mathrm{a}}$ ed. 1958).

${ }^{44}$ Cf. Teresa Leonor M. Vale, Escultura Italiana em Portugal, cit., pp. 178-184, Teresa Leonor M. Vale, "As Estátuas de Santo Antão do Tojal. Contributo para um panorama da importação de escultura barroca genovesa para Portugal", Artis - Revista do Instituto de História da Arte da Faculdade de Letras de Lisboa, 5, 2006, pp. 237-270, Teresa Leonor M. Vale, Scultura Barocca Italiana in Portogallo. Opere, artisti, committenti, Roma, Gangemi Editore, 2010, pp. 67-75.

${ }^{45}$ Como a sua presença na listagem da comunidade italiana de Lisboa desse ano atesta - cf. ANSL, Caixa VII, Doc. 42.1. fl. 2, publ. por Teresa Leonor M. Vale, Escultura Italiana em Portugal, cit., Documento 7. 
O mesmo Giovanni Battista Garvo - nascido em Bissone (Canton Ticino), a 8 de Outubro de 1644, e que viria a falecer em Lisboa, no dia 26 de Agosto de $1692^{46}$ - recebe, no mês de Agosto de 1689, dos padres inacianos do colégio de Santo Antão de Lisboa, a quantia de $200 \$ 000$ reis como sinal "para mandar vir huma partida de pedra branca, uermelha e uerde e brocatel de França de Genoua na nao Loreto para o retabolo da capella mor" ${ }^{\prime \prime}$. Este breve excerto evidencia como Giovanni Battista Garvo era não apenas mestre pedreiro e escultor, mas também detentor de uma actividade de carácter mais comercial, encontrando-se essa vertente da sua actividade associada a um encomendador tão relevante como era a Companhia de Jesus em Portugal na segunda metade de Seiscentos ${ }^{48}$.

Esta pedra, que Garvo fazia chegar desde o porto genovês a Lisboa, destinava-se à obra do retábulo-mor da igreja, de que hoje subsistem apenas duas monumentais colunas torsas em mármore da Arrábida e os respectivos capitéis em mármore branco, vindos de Génova, aplicados no retábulo da igreja paroquial de S. José, no Largo da Anunciada em Lisboa ${ }^{49}$. Nos primeiros anos do século XVIII observavam-se, integradas em nichos distribuídos pela nave e capela-mor da igreja do colégio de Santo Antão-o-Novo, três estátuas de

${ }^{46}$ Cf. Elisabetta Monteni, "Garvo", Dizionario Biografico degli Italiani, Vol. LII, Roma, Istituto della Enciclopedia Italiana, 1999, pp. 402-405.

${ }^{47}$ Arquivo Nacional da Torre do Tombo (Lisboa), Cartório dos Jesuitas, Caixa 16, Maço 11, Doc. 92, cit. por Fausto Sanches Martins, A Arquitectura dos Primeiros Colégios Jesuitas de Portugal: 1542 - 1759. Cronologia, Artistas, Espaços, Vol. 1, Porto, Tese de Doutoramento Apresentada à Faculdade de Letras da Universidade do Porto, 1994, p. 417 (texto policopiado).

${ }^{48}$ Acerca dos Garvo e da sua actividade em Lisboa, veja-se Teresa Leonor M. Vale, "Os Garvo. Uma família de artistas italianos em Lisboa e o seu papel no contexto da arte portuguesa de Seiscentos e Setecentos”, Nunziatella Alessandrini, Pedro Flor, Mariagrazia Russo, Gaetano Sabatini, (coord.), 'Le nove son tanto e tante buone, che dir non se po'. Lisboa dos Italianos: Arte e História (sécs. XIV-XVIII), Lisboa, Cátedra de Estudos Sefarditas A. Benveniste, 2013, pp. 175-187.

${ }^{49}$ Cf. António Lopes S.J, Roteiro Histórico dos Jesuitas em Lisboa, Braga, Livraria A. I. - Editorial A. O, 1985, p. 24. 
apóstolos (a que se juntava uma quarta provisoriamente em estuque) e uma outra estátua, figurando um evangelista, todas esculpidas em mármore branco. Tendo em conta a existência destas quatro estátuas pétreas, podemos com segurança afirmar que o programa iconográfico-escultórico se constituía de um apostolado complementado pelos dois evangelistas que não são simultaneamente apóstolos, afinal o que já havíamos reconhecido na igreja de Nossa Senhora do Loreto.

Seguindo uma vez mais o texto do autor anónimo que, pouco depois de 1706, descreve a igreja do colégio jesuíta, reconhecem-se na nave: “(..) dous nichos em que se vem collocadas duas imagens de dous Apostolos (...) " e ainda “(...) hum nicho com a Imagem de hum Apostolo que ha-de ser de marmore branco, posto que entretanto he de estuque (...) Já na capela-mor, onde se localizava o túmulo da condessa fundadora, D. Filipa de Sá (também ele oriundo de Génova), observavam-se as estátuas de um apóstolo - "E sobre o arco que recolhe a sepultura da fundadora tem lugar hum nicho muy perfeyto forrado de marmore vermelho que dá lugar a huma imagem do Principe dos Apostolos Sam Pedro, lavrada em alvissimo marmore de Genova (... $)^{152}$ - e de um evangelista - "(..) hum nicho que fecha em arco, forrado pella parte interior de marmore vermelho em que assenta a imagem de hum Evangelista (...) $)^{\text {"3 }}$.

Apesar de apenas uma destas estátuas ser claramente referida como sendo italiana, cremos que do texto se pode depreender terem sido todas as mencionadas importadas de Génova e que mesmo aquela, que se encontrava provisoriamente em

${ }^{50}$ História dos Mosteiros, Conventos e Casas Religiosas de Lisboa, Vol. 1, (edição de Durval Pires de Lima), Lisboa, Câmara Municipal de Lisboa, 1950, p. 433.

${ }^{51} \mathrm{Id}$.

${ }^{52}$ História dos Mosteiros, Conventos e Casas Religiosas de Lisboa, Vol. 1, pp. $437-$ 438.

${ }^{53}$ História dos Mosteiros, Conventos e Casas Religiosas de Lisboa, cit., Vol. 1, p. 437. 
estuque, terá, eventualmente, sido substituída pela correspondente em mármore, ainda que o apostolado tenha ficado incompleto ${ }^{54}$. Do conjunto de estátuas genovesas de Santo Antão, sobrevivem hoje certamente aquelas figurando S. Pedro e S. Paulo, colocadas desde 1811 diante da fachada sul do Hospital de S. José.

Uma última nota, no contexto da temática do presente texto, a escultura barroca italiana na igreja do Loreto de Lisboa, é devida a uma segunda geração de protagonistas, activa já na centúria de Setecentos. Tal intervenção regista-se nomeadamente através do filho de Filippo Parodi, Domenico (1672-1742), a quem os provedores da igreja encomendam balaustradas de mármore ${ }^{55}$ e a quem se deve igualmente o projecto que presidiu à realização das armas pontifícias e respectivos anjinhos tenentes, que se observam sobre a porta principal do templo dos italianos.

Foi a investigação de Fausta Franchini Guelfi que clarificou a questão da autoria desta obra, recorrendo ao texto de Carlo Giuseppe Ratti (na sua versão do manuscrito de 1762 já atrás mencionada), no qual se refere que a mesma teria sido executada por Francesco Biggi "con disegno però di Domenico Parodi" "56. Assim sendo, e ao contrário do que anteriormente pensáramos e do que outros autores haviam

${ }^{54}$ Seria completado mais tarde, com a intervenção de um escultor italiano activo em Lisboa, João António Bellini de Pádua - cf. Teresa Leonor M. Vale, Um Português em Roma, Um Italiano em Lisboa. Os escultores setecentistas José de Almeida e João António Bellini, Lisboa, Livros Horizonte, 2008, pp. 87-89.

${ }^{55}$ ANSL, Masso Cartão, Fasc. A, Doc. 8, ref. por Sergio Filippi, cit., p. 96.

${ }^{56}$ Carlo Giuseppe Ratti, Storia dePittori, Scultori ed Architetti Liguri e de' Forestieri che in Genova Operarono secondo il Manoscrito del 1762, (...), p. 107 - cf. Fausta Franchini Guelfi, "Sculture Genovesi del Settecento a Lisbona”, Studi di Storia delle Arti. Numero Speciale in Onore di Ezia Gavazza, Genova, Sagep Editrice, 2003, p. 156 e também Fausta Franchini Guelfi, "Sculture Genovesi per il Portogallo nel Seicento e nel Settecento”, Teresa Leonor M. Vale, Pedro Flor, (coord.), A Escultura em Portugal. Da Idade Média ao inicio da Idade Contemporânea: história e património. Actas, Lisboa, Fundação das Casas de Fronteira e Alorna, 2011, pp. 223-238. 
proposto $^{57}$, o conjunto terá sobrevivido ao abalo sísmico de 1755 e ao subsequente incêndio que atingiu a igreja, denotando porém as pernas (em particular aquela esquerda) do anjo tenente do lado direito evidentes estragos. Filho do mais célebre escultor Filippo Parodi, Domenico - mais pintor do que escultor - veio a herdar o atelier paterno e contou, durante a sua actividade com a muito frequente colaboração de Francesco Biggi (1667-1728), com quem aliás realizou igualmente uma outra obra que se conserva em Lisboa, o busto de D. João V, constante das colecções do Palácio Nacional da Ajuda ${ }^{58}$.

Dos retábulos, mor e laterais, realizados com o "marmore di Carrara del più bianco si potrà trovare" e que seriam certamente "cosa curiosissima e delle piu belle", nada restou após o terramoto de 1755 e do inteiro apostolado que, juntamente com dois evangelistas, animava os nichos da nave, também nada subsiste.

Lembram as estátuas, tão-só as pinturas em grisaille, realizadas cerca de 1783 por Cirillo Volkmar Machado (1748-

${ }^{57}$ A obra havia sido atribuída a artistas tão diferentes como Gian Lorenzo Bernini (1598-1680), Francesco Borromini (1599-1667) e Antonio Canova (1757-1822), designadamente por A. Raczynski, Les Arts au Portugal: Lettres Adressées à la Societé Artistique et Scientifique de Berlim, et Accompagnées de Documents, Paris, J. Renouard \& Cie., 1846, p. 287, A. Raczynski, Dictionnaire Historico-Artistique, Paris, J. Renouard \& Cie., 1846, p. 28 e p. 37, Francisco Marques de Sousa Viterbo, Dicionário Histórico e Documental dos Arquitectos, Engenheiros e Construtores Portugueses, 2a edição, Vol. I, Lisboa, Imprensa Nacional - Casa da Moeda, 1988, p. 104 (1ª edição 1899 - 1922) e Júlio de Castilho, cit., pp. 37-39.

${ }^{58}$ PNA, Inv. 56.577- a propósito desta obra Cf. Fausta Franchini Guelfi, Domenico Parodi (1672-1742) e Francesco Biggi (1667-1728) Ritratto di Giovanni V di Portogallo, Sandra Vasco Rocca, Gabriele Borghini, (dir.), Giovanni V di Portogallo (1707-1750)e la Cultura Romana del Suo Tempo, Roma, Àrgos Edizioni, 1995, p. 19, Teresa Leonor M. Vale, Escultura Barroca Italiana em Portugal. Obras dos séculos XVII e XVIII em colecçôes públicas e particulares, cit., pp. 115-118 e Teresa Leonor M. Vale, Scultura Barocca Italiana in Portogallo. Opere, artisti, committenti, cit., pp. 153-155. 
1823) e sua oficina ${ }^{59}$, as quais não são sequer uma memória visual das esculturas genovesas - pois reportam-se sim ao monumental apostolado da basílica romana de S. João de Latrão, que em Portugal se divulgara pela circulação de gravuras - mas apenas uma remota evocação da presença dos apóstolos e evangelistas, cumprindo "sem mácula o seu papel de animadores da pretendida cenografia do corpo da igreja", na feliz expressão de Vítor Serrão ${ }^{60}$, como já o haviam feito antes as estátuas barrocas.

${ }^{59}$ É a existência de um desenho relativo à capela-mor da igreja do Loreto datado precisamente de 1783 , que permite situar no tempo a intervenção de Cirillo no templo dos Italianos - informação gentilmente facultada pela Dra. Sofia Braga, que tem em preparação uma dissertação de Doutoramento em História da Arte (na Faculdade de Letras da Universidade de Lisboa) dedicada a Cirillo Volkmar Machado.

${ }^{60}$ Vítor Serrão, "A pintura antiga na igreja de Nossa Senhora do Loreto", cit., p. 171. 